\title{
A Model Developing e-Learning for M.5 English Language Teaching Using Cooperative Learning, Scaffolding and MIAP Learning Process (e-CL ScafMiap)
}

\author{
H. Wiphasith, R. Narumol, and C. Sumalee
}

\begin{abstract}
English language learning for most of the Thai students is rather boring, difficult, and not highly motivating because they do not realize the importance of learning a language used globally. These problems affect the effectiveness of learning. Students' achievement in language skills is unsatisfactory. To solve this problem, the teaching and learning of English in traditional classroom should be exciting and more challenging. Electronic media is a suitable alternative to the traditional classroom approach as it promotes students' learning, attracts their attention, motivates them, and keeps them interested for the duration of the lesson. However, the e-learning process should have a learning environment that allows students to use different methods and styles for learning, and offers additional resources to support learning. One of the objectives of this research is to develop an e-learning model for teaching English to M.5 students using cooperative learning, scaffolding and the MIAP learning process. The content design and courseware development processes follow the ADDIE model, and are presented by the MIAP learning process. This model consists of eight modules as follows: student module, teacher module, clustering module, STAD module, content module, communication module, scaffolding module and evaluation module.
\end{abstract}

Index Terms-E-learning, cooperative learning, scaffolding, MIAP.

\section{INTRODUCTION}

From the results of the English test scores of the M.6 students in the last four years of Ordinary National Educational Test (O-NET) [1], the average percentage of the scores were $23.98,19.22,21.80$ and 22.13 respectively. Above information shows that Thai students have lower scores in English tests when compared to the standard score (less than 50 percent). Thai students have low Basic English language skills, including pronunciation, reading, listening and writing. In addition, they lack the patience, confidence, enthusiasm, and motivation to master the necessary skills. Besides, their attitude toward English is rather negative. They dislike English [2]-[4]. It also found that the primary factor that impedes the learning and teaching of English is restricted mostly to the classroom [5].

Manuscript received March 20, 2014; revised May 20, 2014. This work was supported in part by the Suranaree University of Technology, Thailand and Rajamangala University of Technology Isan, Surin Campus, Thailand.

H. Wiphasith and R. Narumol are with the School of Information Technology, Social Technology, Suranaree University of Technology, Thailand 30000 (e-mail: wiphasith@ hotmail.com, narumol.n@ sut.ac.th).

C. Sumalee is with the Education Technology, Faculty of Education, Khon Kaen University, Thailand 40002 (e-mail: sumalee@kku.ac.th).
Recent advancements in information technology have influenced change in teaching and learning styles. Development of electronic materials such as Web Based Instruction (WBI), Computer Assisted Instruction (CAI), and e-learning, has allowed technology to be used in supplementary, complementary and comprehensive roles, presenting and transferring knowledge to learners, helping raise the quality of education, and enhancing teaching and learning processes. Electronic media is able to deliver content with text, images, audio and video, allowing students to respond to learning immediately, which other media cannot accomplish. In addition, it is important to note that students can learn at anytime and from anywhere and this flexibility can encourage individual differences among students [6]. Nowadays, there are many schools and programs adopting a large quantity and variety of electronic media to help in teaching English. They help encourage students to have an interest in learning, create a fun learning environment, and provide context to the content, resulting in better understanding and retention. However, these materials haven't supported learners' achievements significantly enough to say that they have mastered the English language. This may be due to the lack of support among the learners; most courses and programs do not emphasize or accommodate cooperative learning. If learning English is to be successful, the students need to share thoughts with others, help teammates learn, and make meaningful interactions. For the teaching environment, learning styles and teaching methods to be compatible with the learners, it is essential that teachers take into account student-student interaction.

Nowadays, there are many learning processes to help students learn and get other skills, such as lecturing, discussion, practice, demonstration, simulation, projects, etc. [6]-[8]. In general, the teaching and learning has focused on the interaction between the learners and the teacher and the learners and the content. However, the learning is quite often focused on competition among learners, resulting in a lack of cooperation and assistance. Generally, educators are not interested in the interaction between the learner and other learners, and their interaction with the work [9]. M.A. Gabriel [10] identified that students interact in workgroups, and share responsibilities with others to reduce anxiety in the classroom, because it offers the opportunity for students to have discussions, create human relationships and participate in critical thinking with other learners. In addition, students often produce better results than when they work alone. Therefore, education should encourage students to participate in thinking and problem solving as part of the self-knowledge creation process. Cooperative learning is a 
suitable alternative teaching method supporting the approaches that do not have sufficient inter-learner communication.

Cooperative learning is a way to create human relationships between the learners [11], and build a learning environment for the students to learn together in small groups [12]. By having students of different levels of ability (excellent, medium and poor) work together in groups [13], they share thoughts and ideas with others, learn emotional states and sentiments of each team member, [11], [14]-[16], and it also encourages students to share learning resources, offers encouragement to other learners, and creates harmony while learning new skills. Moreover, cooperative learning can keep students interested and enthusiastic, make learning fun, and encourage students' social skills [12]. It also fosters learners' adaptability and communication skills. Although cooperative learning offers many advantages over the traditional learning models, some students still have problems in studying. They were not interested in the assignments or activities provided. Furthermore, some of them could even influence the group's members positively or negatively. If it is negative influence, the cooperative learning is a failure; at least, the learning achievement might not be met. To mitigate this possibility, it is necessary that the teaching administration and management processes be focused on student-centered learning, allowing students to gain knowledge and develop themselves. Consequently, teachers must also develop a set of skills to enhance students' learning (Scaffolding). This includes preparing learning resources to support learning and help learners to learn more [17]. In addition, the instructor must provide learning experiences consistently with learning objectives and show competency in the development of learners [18].

The MIAP learning process is an educational framework which is designed to improve learners' performance. The first step is to get students motivated to learn. That is to have a strong desire to learn. Then provide opportunities for learners to use their knowledge in problems solving, to achieve success in learning. By bringing the features of cooperative learning, Scaffolding and the MIAP learning process into English learning on electronic media, there may be a way to teach, that ensures high-performance English learning for students.

Nevertheless, based on the results of the aforementioned studies, researchers are bringing the features of cooperative learning, with STAD techniques applied, to electronic media, where the contents are presented by the MIAP learning process. In addition, they intend to provide an online learning environment that offers support for students' learning. In summary, this paper presents a model for the development of e- Cooperative learning integrated with scaffolding and MIAP learning processes (e-CL ScafMiap).

\section{LITERATURE REVIEW}

\section{A. Cooperative Learning}

Cooperative learning is focused on providing the opportunity for interaction within the group of four or five members by the teacher. Through this interaction, students support and work together to solve problems to achieve a specific goal [14]-[16]. Members participate in group work and discussions, share learning resources, and encourage each other to succeed [15]. Each team consists of a mix of high, average, and low achievers, so high achievers will have to help lower achievers [19]. Each member of a team is responsible not only for their own learning but also for the learning of all the members in their own group because the group's success depends on the individual's success [15]. This promotes teamwork which is an essential skill in life. The concept of cooperative learning is popular, and is used in multiple frameworks and models, such as Students Teams Achievement Division (STAD), Team Assisted Individualization (TAI), Team Games Tournament (TGT), and Jigsaw and Investigation Group (GI) [15], [20], [21].

\section{B. Students Teams Achievement Division (STAD)}

STAD involves forming learning teams that are mixed in performance level, gender, and ethnicity to work together in a group [22]. The teacher assigns students to teams of four or five members per learning group -- four is preferable; make five-member groups only if the class is not divisible by four [13]. If there are four members per team, the team will ideally consist of one high, two average, and one low achiever; if there are five members, it will consist of one high, three average, and one low achiever [22]. After the group assignment, the teacher presents a lesson or unit to the entire class, and students work within their group to make sure that all group members have mastered the lesson [22]. If students have questions, they would ask a teammate before asking the teacher. Finally, all students take tests individually, at which time they may not help one another [13]. The scores the students contribute to their teams are based on the degree to which they represent an improvement over each student's own past average. The teams with the highest scores are recognized in a weekly class newsletter [22].

\section{Scaffolding}

Scaffolding is a teaching concept proposed by Vygotsky, where instruction should be provided to learners if they are unable to solve a problem. They can be helped to achieve with a competent teacher, other students or someone overseeing the learning. However, Vygotsky believed that learning is strongly influenced by social interactions which take place in meaningful contexts [23]. As the learner's knowledge and learning increases, the teacher has to gradually reduce the support [24]. J. Hannafin [25] defined four scaffolds which form the scaffolding support framework:

1) Conceptual scaffolding

2) Metacognitive scaffolding

3) Procedural scaffolding

4) Strategic scaffolding

In addition, S. Charunee [26] has proposed an additional scaffold, expanding upon J. Hannafin's original four: Creative scaffolding.

\section{MIAP Learning Process}

The MIAP learning process refers to a four-step process based on the principles of education experience. It is this process that teachers use to organize the learning experience. 
It includes four steps as follows: [18]

1) Motivation: (M) The aims of this step are to encourage students to take an interest in, and solve the problem: to encourage students to want to learn and lead the students into the subject with that intention. This intention and motivation should be maintained throughout the lesson to keep the students engaged, and therefore, improve knowledge retention.

2) Information: (I) This step is the actual delivery of the content to the students. As part of this, the content should be sorted and separated into smaller chunks, appropriate for what the students are able to absorb and retain.

3) Application: (A) To make sure the students have a better understanding of the content, they practice using the new knowledge to solve specific problems. At this stage, the learners need to be checked, and given the opportunity to use the knowledge in the process of finding a solution to a problem, ensure the students have understood the lesson, and to review their knowledge.

4) Process: (P) The final step is to monitor and evaluate of achievement of the objectives. If the objectives are not achieved, the instructor will need to make adjustments until the students properly understand the content, and complete it.

\section{MeTHODOLOGY}

The research methodology of the ADDIE model has steps as follows: [27]

\section{A. Analysis: (A)}

In this step, researchers perform the following analyses: needs analysis, learner analysis, and task analysis. The first step is needs analysis of the mentioned problems with Thailand's education system, including the methods and techniques of teaching. The next step is analyzing the learners' current levels of basic knowledge of English by questioning and collecting data from the teachers who teach English. The last step is task analysis, which consists of the following analyses: cluster analysts, subtask inventory, prioritizing tasks, and task knowledge.

\section{B. Design: (D)}

After completing the analysis in 3.1, researchers design a model for the development of an e-learning course for teaching English to M5 students using e-cooperative learning, scaffolding and MIAP Learning processes. This design consists of the learning objectives, storyboard of the lesson, scaffolding and system flowchart. These designs are the product of a synthesis of related theories, other research and literature in the analysis phase.

\section{Development: $(D)$}

After the processes were analyzed, researchers develop the M.5 English e-learning system using the resulting model from the Design process. After that, researchers use LearnSquare, a Learning Management System (LMS), to build and code the responsive clustering module. Red 5 is used to develop the video conference capability which is a part of in the communication module, allowing students to communicate and confront each other in a more personal manner, over the computer network. In addition, CourseLab 2.4 is used to create presentations of the content and learning materials, after being evaluated for accuracy by content experts.

\section{RESUlTS AND DisCUSSION}

This model has 8 modules as follows (see Fig. 1):

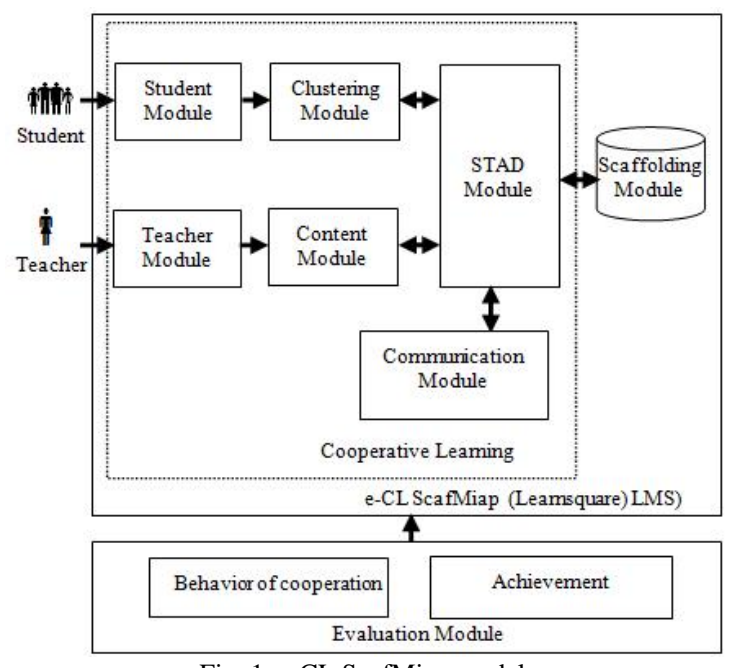

Fig. 1. e-CL ScafMiap model.

\section{A. Student Module}

This module records the basic information and usage history of the students.

\section{B. Teacher Module}

The teacher might provide guidance, consultation and suggestions for student questions. Furthermore, the teacher can monitor and encourage the students to participate in the learning process with understanding, and interact with workgroups. This module provides that functionality.

\section{Clustering Module}

Students are assigned to groups based on various criteria, including ranking from top to bottom on some measures of academic performance (e.g. online pretest of each lesson). This module is controlled by the teacher.

\section{STAD Module}

The STAD module implements part of the cooperative learning concepts, in which students are assigned to four- or five-member teams, that are mixed in academic performance (high, averages, low), to work together throughout the lessons. Students explain answers to one another instead of just checking each other's answers against the answer sheet. Researchers design a chat room, bulletin boards, and video conference capabilities, so that learners can use communication and interaction within the group.

\section{E. Content Module}

Multimedia content is presented with this module, which also includes an implementation of the MIAP learning process consisting of four following steps:

1) Motivation (M): This phase motivates the students' interest. The courseware is designed and developed 
using multimedia such as characters, text, and graphics. Early in the learning process, the learners are motivated by this multimedia. In addition, a chat room is built in to help the students and teachers discuss the topics to be studied.

2) Information (I): Courseware content pieces (e.g. presentations, graphics, animations, etc.) are sorted in a linear fashion, according to the lesson plan. The teacher will determine the time and the content is presented to the students. Characters or cartoons are used in the presentation materials of each lesson, as tools to attract the attention of the students as well as to motivate them.

3) Application (A): Check that the behavior of learners has changed according to the set objectives, by using exercises, quizzes, and post-lesson tests (the post-lesson tests are individual; they may not help one another). Teachers observe students' behavior and participation in the assigned work from questions, comments, expressions and other communications made by learners through the learning support system facilities such as chat rooms and bulletin boards.

4) Process (P): The teacher evaluates each student's activities and results. Then reports the student's various scores at the end of each lesson (pretest, exercise, quizzes, and post-test) to make each student aware of their own and their teammates' successes. These scores are communicated electronically via the Evaluation module.

\section{F. Communication Module}

The majority of inter-student communications are handled by this module, which facilitates the class chat room, the group chat room, (The group chat room can be only be used after the instructor has assigned the students into groups.) bulletin boards and forums, and the group video conference capabilities.

\section{G. Evaluation Module}

As part of each student's learning outcome evaluation, the scores for participation, individuals and groups, and overall statistics for each lesson need to be calculated and communicated. The Evaluation module handles these tasks.

\section{H. Scaffolding Module}

The researchers apply Hannafin's and Chajunee's scaffolding techniques to design this module. To provide support and further encouragement to students, the module has five characters for helping and guiding learners who have learning problems.

\section{CONCLUSION AND FURTHER RESEARCH}

This paper outlines and discusses the development of an e-learning course for teaching the English language to M.5 students using cooperative learning, scaffolding and MIAP Learning processes. The system has eight modules as follows: student module, teacher module, clustering module, STAD module, content module, communication module, scaffolding module, and evaluation module. The further research, Next step we will bring this model to develop e-learning, implementation and evaluation. In addition, this research should be design agent intelligence module for analyzing of the students' behavior and helping of learners to pertinent.

\section{ACKNOWLEDGMENT}

The researchers would like to thank the teachers and experts who participated in this study. In addition, the researchers gratefully acknowledge the support of the Suranaree University of Technology Nakhon Ratchashima, Thailand and Rajamangala University of Technology Isan, Surin Campus, Thailand.

\section{REFERENCES}

[1] The National Institute of Educational Testing Service. (February 2013) Ordinary National Educational Test of grade 6 academic year 2555 (A.D. 2012). [Online]. Available: http://www.onetresult.niets. or.th/AnnouncementWeb/Notice/FrBasicStat.aspx

[2] H. Nareenart, "Using films to develop English skills: the use of James Mckernan's time cycle process of the action research model," Educational Measurement Mahasarakham University, vol. 17, no. 1, pp. 187-199, July 2012.

[3] Z. Xu. (February 2012). Problems and strategies of teaching English in large classes in the People's Republic of China. Expanding horizons in teaching and learning. [Online]. Available: http://otl.curtin.edu.au/professional_development/conferences/tlf/tlf20 01/xu.html

[4] W. Hiew, "English language teaching and learning issues in malaysia: learnings' perceptions via facebook dialogue journal," Arts, Science \& Commerce, vol. 3, no. 1, pp. 11-19, January 2012.

[5] P. Fasawang, "The three-step Model: a guideline for teaching English oral communication," Executive Journal, vol. 31, no. 4, pp. 41-45, October-December 2011

[6] M. Suwit and M. Orathai, 19 How to develop knowledge and skills, 4th ed., Bangkok: Phappim, 2002, p. 161.

[7] W. Preyaporn, Techniques and Methods of Vocational Education Teaching, Bangkok: Pimdee, 2011, pp. 114-118.

[8] S. Sarote, Educational Innovation that Focus on Learner-Centered, Bangkok: Book Point, 2003, pp. 31-32.

[9] K. Tissana, Instructional Science, Bangkok: Chulalongkorn University Press, 2012, pp. 99-100.

[10] M. A. Gabriel, "Learning together: exploring group interactions online," Distance Education, vol. 19, no. 1, pp. 54-72, 2004.

[11] S. Chaiwat, 80 Educational Innovations that Focus on Learner-Centered, Bangkok: Kanax Interoperation, 2009, p. 198.

[12] T. Pichai, "Educational Innovation that Focus on Learner-Centered," Ph.D. dissertation, Dept. Communications and Technology, Bangkok, Chulalongkorn Univ., Thailand, 2004.

[13] R. E. Slavin, Student Team Learning, Center for Social Organization of School: The Johns Hopkins University, 1980, p. 21.

[14] A. F. Artz and C. M. Newman, "Cooperative Learning," Mathematics teacher, vol. 83, pp. 448-449, 1990.

[15] R. E. Slavin, Synthesis of Research on Cooperative Learning Educational Leadership, vol. 48, no. 5, pp. 71-82, 1991

[16] S. J. Thousand, Creative Collaborative Learning, 2nd Ed., Paul Brookes, Baltimore, 2002, pp. 3-16.

[17] C. Sumalee, Education Technology: Principle Theories to Practices, Khon Kaen: Klang-nana Witthaya, 2008, p. 311.

[18] S. Suchat, Techniques and methods of Professional Teaching: MIAP, Bangkok: King Mongkut's University of Technology North Bangkok, 2008.

[19] R. Wattana, Lesson Plan that Focus on Learner-Centered, Bangkok: L.T Press, 1999, pp. 34.

[20] S. Sharon and Y. Sharon, "Group Investigation Expands Cooperative Learning," Educational Leadership, vol. 47, no. 4, pp. 17-21, 1989.

[21] C. H. Dwight, Cooperate and Feel Great: Cooperative Learning Training Manual, University press of America. Lanham, Maryland, 2005, p. 57.

[22] R. E. Slavin, "Student Centered and Constructivist Approaches to Instruction," Educational Psychology, Boston, MA: Allyn \& Bacon, 2003, ch. 8, pp. 254-288.

[23] P. L. N. Kiong and H. T. Yong. (April 2012). Scaffolding as a Teaching Strategy to Enhance Mathematics Learning in the Classrooms. [Online]. Available:

http://www.ipbl.edu.my/bm/penyelidikan/2001/2001_8_paul.pdf. 
[24] E. Raymond, "Cognitive Characteristics," Learners with Mild Disabilities, 2002, pp. 169-201.

[25] J. Hannafin. (April 2012). Resource-Based Learning Environments: Methods and Models. [Online]. Available: http://www.ascilite.org.au/conferences/perth97/papers/Hannafin/Hann afin.html.

[26] S. Charunee, "The design of scaffolding to promote creativity," Education, vol. 33, no. 4, pp. 1-9, 2010.

[27] B. Seel and Z. Glasgow, Making Instructional Design Decisions, 2nd., Upper Saddle River, NJ: Merrill, 1998, pp. 7-317.



Wiphasith Hiranrat is 32 years old. She was born in Thailand. She graduated with a bachelor's of degree in computer science, Faculty of Information Science from Mahasarakham University (MSU), Thailand in March 2005. She graduated with a diploma in teaching from the Faculty of Education at Sukhothai Thammathirat Open University (STOU), Thailand in November 2004 And she graduated with a master's degree in computer technology from the Faculty of Technical Education at King Mongkut's University of Technology North Bangkok (Kmutnb), Thailand in January 2008.

Now she is studying D.I.S. (information technology) School of Information Technology, Suranaree University of Technology, Thailand. Her research interests include e-learning, learning management for disabled children etc.

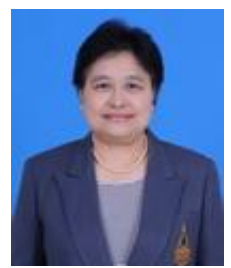

Narumol Ruksasuk is 56 years old. She was born in Thailand. She graduated with a bachelor's of degree in Library Science, Faculty of Liberal Arts, Thammasat University (TU), Thailand in 1980. She graduated with a master's degree in library science, Faculty of Arts, Chulalongkorn University (CU), Thailand in 1985. And she graduated with Ph.D. in library and information science, School of Information Sciences, University of Pittsburgh, U.S.A. in 2000.

Now she is a lecturer at School of Information Technology, Suranaree University of Technology, Thailand. Her research interests include e-learning, etc.

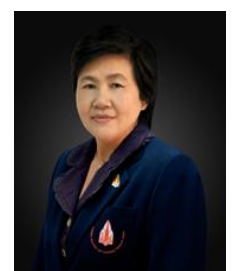

Sumalee Chaijaroen was born in Thailand. She graduated with a bachelor's of degree in education (elementary education), Faculty of Education at Khon Kaen University (KKU), Thailand in 1981 and a bachelor's of degree in education (education technology), Faculty of Education at Khon Kaen University (KKU), Thailand in 1985. She graduated with a master's degree in education technology, Tsukuba University, Japan in 1997. And she graduated with Ph.D. education technology, Tsukuba University, Japan in 2001.

Now she is a lecturer at education technology, Faculty of Education at Khon Kaen University (KKU), Thailand. Her research interests include management of learning, innovation education, education technology, etc. 